10 Kiecolt-Glaser JK, Garner W, Speicher C, Penn GM, Holliday J, Glaser R. Psychosocial modifiers of immunocompetence in J, Glaser R. Psychosocial modifiers of immunoco
medical students. Psychosom Med 1984;46:7-14.

11 Baker GHB, Irani MS, Byrom NA, Nagvekr NM, Wood RJ Hobbs JR. Stress, cortisol concentrations and lymphocyte Hobbs JR. Stress, cortisol concentration
subpopulations. Br Med f 1985;290:1393.

12 Locke SE, Kraus L, Lesserman J, Hurst MW, Heisel JS Williams RM. Life change stress, psychiatric symptom an natural killer cell activity. Psychosom Med 1984;46:441-53

13 Moldofsky H, Lue FA, Eisen J, Keystone E, Gorczynsky RM The relationship of interleukin- 1 and immune functions to sleep in humans. Psychosom Med 1986;48:309-17.

14 Murphy E, Brown GW. Life events, psychiatric disturbance and physical illness. Br f Psychiatry 1980:136:326-38.

\section{AIDS: act now, don't pay later}

SIR,-Dr D E B Powell (20 September, p 758) maintains that the acquired immune deficiency syndrome is "first and foremost related to male homosexuality" and that health education should carry the wording "homosexual activity may damage your health." $\mathrm{He}$ is correct that most cases in the United Kingdom and the United States occur in homosexual men, but this is not so world wide. In certain African countries the sex distribution of sufferers is virtually equal. Surely the important point about the disease is that the main mode of transmission is through sexual intercourse with an infected partner. Health education should concentrate on ways in which this message can be made clear. To use emotive terms about homosexuality damaging health is shortsighted since $(a)$ it supposes that all homosexuals behave in the same way and are at equal risk of acquiring human immunodeficiency virus (HIV) infection and $(b)$ it suggests to heterosexuals that they are not at risk this is going to be increasingly incorrect.

Dr Powell also raises the question of whether three cases of AIDS in drug abusers constitutes enough of a problem to allow us also to concentrate on this group. The important issue is not the total number of cases but the prevalence of antibodies to HIV in such populations. So far HIV infection in this group has been more of a problem in the United States and Europe. Last year survey indicated that $76 \%$ of addicts in Italy (the figure was $6 \%$ in 1980) and $32 \%$ in Switzerland had antibodies to HIV. In the UK this was $10 \%$ (a fourfold increase in one year) but with pockets of much higher rates, such as $50 \%$ in Edinburgh. The next wave of the epidemic of AIDS in the UK will undoubtedly occur in addicts. This is why we need to concentrate on them and produce effective health education.

We must not allow ourselves to make the same mistake as occurred with the rising prevalence of HIV in homosexual men. AIDS did not start to occur in homosexual men in America until the prevalence of HIV had reached $20-25 \%$ in 1982 . A that time probably only about $4 \%$ of London's homosexual population had antibodies to HIV, yet we did not mount a national health education programme until 1986, when the prevalence was over $25 \%$ and more than 300 cases had occurred. We ignored the American experience and did no act at an early stage; and we must not let this happen again. We need to act now with effective health education and not when the three cases are 30 or 300 . Then control will be so much harder.

Department of Genitourinary Medicine Middlesex Hospital Medical School, London WIN 8AA

M W ADLER

SIR,-Dr D E B Powell (20 September, p 758) does a great disservice to medicine and the acquired immune deficiency syndrome (AIDS) by assuming that homosexual activity and community are the only sources of AIDS. Attitudes like this in the
United States delayed research grants and work on AIDS by years. We have only to look at the accounts of AIDS in Africa ${ }^{12}$ and the United States to avoid making fatuous assumptions and comments. If we are unable to learn from the experience of other nations no doubt we will end up paying more, as you suggest in your excellent and timely leading article (9 August, p 348). We have to accept that AIDS is here and does not respect sex or sexuality. Available information indicates that $3-4 \%$ of the current caseload in North America and Europe has arisen from heterosexual spread. ${ }^{1}$ How can Dr Powell assume that if homosexuality was "cured" AIDS would disappear? We have to be dispassionate about this debate and not make the sexuality of an individual an issue. One of the reasons why help (financial and otherwise) has not been forthcoming is because the "moral majority" dictates terms. It is not a homosexual disease. Had the disease initially attacked heterosexuals and then spread to other groups I wonder if Dr Powell would have reacted by saying: "Heterosexual activity may damage your health"?

Sufferers of AIDS need help and they need it now, along with our compassion and understanding. Everyone needs information and education on AIDS and needs it now if we are to make any headway in combating the disease. The medical profession with its longstanding liberal traditions needs to be educated perhaps even more than the man on the Clapham omnibus.

Hellingly Hospital

Hailsham,

East Sussex BN27 4ER

DiNesh BHUGRA

Pinching AJ. AIDS and Africa: lessons for us all. Journal of the Royal Society of Medicine 1986;79:501-3.

Bigger RJ. The AIDS problem in Africa. Lancet 1986;i:79.

\section{Psoriasis}

SIR,-Dr R H Champion's admirable review of psoriasis (28 June, p 1693) and the subsequent letter from Dr C E M Griffiths and colleagues (26 July, p 266) has highlighed the difficulty investigators engaged in psoriasis research face in deciding whether the particular anomaly they are investigating represents a genuine primary defect or simply a secondary effect. Unfortunately, despite claims to the contrary, ${ }^{12}$ the cause of the characteristic epidermal proliferation present in psoriasis remains elusive.

Dr Janet Marks's comments (23 August, p 509) on the clinical effects of cyclosporin $A$ are interesting, particularly her reference to clinical efficacy at dosages unlikely to affect the immunological mechanisms postulated for the pathogenesis of psoriasis. ${ }^{3}$ A possible alternative explanation for cyclosporin A's activity in psoriasis already exists, since cyclosporin $\mathrm{A}$ has been shown to be a potent inhibitor of the intracellular calcium dependent regulator protein calmodulin-a property which may be crucial to its action on $\mathrm{T}$ lymphocytes. ${ }^{4}$ This may be relevant, because the calmodulin content of psoriatic epidermis has been shown to be about twice that found in normal controls ${ }^{5}$ and to fall once the psoriasis is treated. ${ }^{6}$ Recently dithranol, one of the principle drugs used topically in psoriasis, has been reported to be a powerful calmodulin inhibitor. ${ }^{7}$ Calmodulin regulates a wide range of calcium dependent processes within the cell, ${ }^{8}$ and binding of cyclosporin A to calmodulin may prevent effective activation of the second messengers and enzymes required for keratinocyte proliferation.

Calmodulin also activates phospholipase A2, the enzyme responsible for the release of arachidonic acid from cell membranes, thereby regulating the production of the inflammatory eicosanoids. Since phospholipase A2 levels are increased in psoriatic epidermis, ${ }^{9}$ calmodulin inhibition should theoretically be able to modify the inflammatory component of psoriasis. This may explain the rapid effect of cyclosporin A on erythrodermic psoriasis noted by Dr R A Wakeel and Dr D C Disk (26 July, p 266).

It is of interest that the antifungal drug ketoconazole has recently been shown to be an effective treatment for scalp psoriasis. ${ }^{10}$ Although the clinical improvement seen has been attributed to inhibition of the growth of pityrosporon yeasts, calmidazolium (R-24571, Janssen Pharmaceuticals), a derivative of another antimycotic imidazole, miconazole, has proved to be such a potent calmodulin antagonist that it is marketed purely for this purpose (as a laboratory reagent).

A wide range of drugs possess calmodulin inhibitory properties, offering a number of considerably less toxic alternatives to cyclosporin $\mathrm{A}$. Whether or not other calmodulin inhibitors may prove to be clinically useful in psoriasis remains uncertain, however, since some drugs with calmodulin antagonistic activity, such as propranolol, appear to aggravate psoriasis. Nevertheless, the remarkable therapeutic effectiveness of cyclosporin $\mathrm{A}$ in psoriasis shows that these agents deserve further investigation.

W F G TUCKER

Department of Dermatology,

Royal Hallamshire Hospital,

Sheffield

S MACNEIL

Department of Medicine,

Clinical Sciences Centre,

Northern General Hospital,

Sheffield

1 Voorhees JJ, Marcelo CL, Duell EA. Cyclic AMP, cyclic GMP, and glucocorticoids as potential metabolic regulators of and glucocorticoids as potential metabolic regulators of
epidermal proliferation and differentiation. F Invest Dermatol 1975;65:179-90.

2 Chapman PH, Rawlins MD, Shuster S. Activity of aryl hydrocarbon hydroxylase in psoriatic skin. Lancet 1979;i: $297-8$

3 Valdimarsson H, Baker BS, Jonsdottir I, Fry L. Psoriasis: a disease of abnormal keratinocyte proliferation induced by $T$ lymphocytes. Immunology Today (in press).

4 Colombani PM, Robb A, Hess AD. Cyclosporin A binding to calmodulin: a possible site of action on $\mathrm{T}$ lymphocytes. Science, 1985;228:337-9.

5 MacNeil S, Tucker WFG, Dawson RA, Bleehen SS, Tomlinson S. The calmodulin content of the epidermis in psoriasis. Clin Sci 1985;69:681-6.

6 Tucker WFG, MacNeil S, Dawson RA, Tomlinson S, Bleehen SS. Calmodulin levels in psoriasis: the effect of treatment. Acta Derm Venereol (Stockh) 1986;66:241-4.

7 Tucker WFG, MacNeil S, Dawson RA, Tomlinson S, Bleehen SS. An investigation of the ability of anti-psoriatic drugs to
SS SS. An investigation of the ability of anti-psoriatic drugs to
inhibit calmodulin activity: a possible mode of action of inhibit calmodulin activity: a possible mode of action
dithranol (anthralin). F Invest Dermatol 1986;87:232-5.

8 Tomlinson S, MacNeil S, Walker SW, Ollis CA, Merritt JE, Tomlinson S, MacNeil S, Walker SW, Ollis CA, Merritt JE,
Brown BL. Calmodulin and cell function. Clin Sci 1984;66: 497-508.

9 Forster S, Ilderton E, Summerly R, Yardley HF. The level of phospholipase $\mathrm{A} 2$ activity is raised in the uninvolved epidermis of psoriasis. Br F Dermatol 1983;108:103-5.

10 Farr PM, Krause LB, Marks JM, Shuster S. Response of scalp psoriasis to oral ketoconazole. Lancet 1985;ii:921-22.

\section{Discrimination against singlehanded general} practitioners

SIR, - We find it incredible that the latest amendment to the Statement of Fees and Allowances for General Practitioners (the Red Book), of July 1986 (SFA 126), has included yet another incentive for GPs to join together to form a group. Page 18a of the Red Book now states that doctors in selected areas (essentially those recognised by the government's inner city policy) who join together to form a group of three or more doctors after 1 April 1984 will be eligible for an incentive payment of up to $£ 4000$ per doctor spread over a year.

We are not aware of any evidence that states clearly that group practices provide a better stan- 